\title{
Komunikowanie polityczne w Ameryce Łacińskiej na przykładzie aktywności prezydenta Wenezueli - Hugo Cháveza
}

\footnotetext{
$\mathrm{D}$
} ynamiczne tempo zmian ekonomicznych, rozwój technologiczny oraz ewolucja latynoamerykańskiej kultury politycznej, jak również wzrastająca rola środków społecznego komunikowania, stanowią przyczyny transformacji modeli komunikowania politycznego w Wenezueli i innych państwach Ameryki Łacińskiej. Wzorując się przede wszystkim na doświadczeniach europejskich i północnoamerykańskich, dostrzegając potencjał Nowych Mediów i serwisów mediów społecznościowych ${ }^{1}$, liderzy polityczni odważnie posługują się strategiami komunikacyjnymi dostosowanymi do oczekiwań i możliwości odbiorców. Nie tylko treść informacji, ale też sposób jej dystrybucji, forma w jakiej dociera do obywateli i sam akt jej przekazywania, stały się istotnymi elementami wartościującymi komunikowanie polityczne.

Według M. Kolczyńskiego znaczącym wyznacznikiem działań w ramach komunikacji politycznej jest ich kontekst, w tym także „poziom rozwoju środków przekazu komunikatów politycznych"² - w przypadku Wenezueli rządzonej przez Hugo Cháveza, mieliśmy do czynienia ze strategiami medialnymi, do których realizacji wykorzystywano intensywnie wszelkie kanały komunikacji z zamiarem wywołania tzw. „medialnego wzmocnienia".

Ponadto, jak zauważają Y. González i A. Cañizález, niektóre z państw Ameryki Łacińskiej tworzą uwarunkowania legislacyjne, które pozwa-

1 Najczęściej używanym przez Hugo Cháveza portalem społecznościowym był Twitter. Konto prezydenta było obserwowane przez ponad cztery miliony użytkowników, komunikaty z lutego 2013 roku są ściśle związane z chorobą nowotworową Cháveza, który za pośrednictwem krótkich wpisów dziękował za gesty wsparcia i zagrzewał obywateli do rewolucyjnej walki zgodnie z hasłem: „¡Hasta la victoria siempre!".

2 M. Kolczyński, Strategie komunikowania politycznego, Katowice 2008, s. 44. 
lają im sprawować władzę za pośrednictwem mediów, tworząc tzw. „państwo-komunikator”, ; konsekwencji mediatyzacja dyskursu politycznego stała się wspólnym mianownikiem dla kilku aktualnie funkcjonujących grup rządzących w Ameryce Łacińskiej (przykłady szczegółowe „pastwa-komunikatora” to Boliwia pod rządami Evo Moralesa, Ekwador pod rządami Rafaela Correa czy Wenezuela pod rządami Hugo Cháveza).

\section{Video-polityka}

Istotnym terminem wyznaczającym zasady komunikowania politycznego w Wenezueli jest video-polityka (znana też jako tele-polityka). O. Sartori akcentuje, iż termin ten odnosi się zaledwie do jednego z licznych przejawów władzy obrazu - do jego obecności w procesach politycznych i do wpływu, który wywiera na prowadzenie działań w sferze publicznej ${ }^{4}$. Legitymizacja władzy na podstawie jej medialnego wizerun$\mathrm{ku}$, jak również przeniesienie znaczenia komunikatu na jego wizualną reprezentację, stwarzają nowe pole analityczne związane z obrazowaniem polityki. Zgodnie z założeniami poczynionymi przez A. Ogonowską w artykule Obrazy polityki. Polityka obrazu, stopień oraz kierunek aktywności i preferencji politycznych obywateli są determinowane przez dwie grupy czynników. Jedna z nich, zorientowana na sprecyzowany efekt, to zespół metod kreowania sceny politycznej i aktorów, nazywana obrazami polityki. Druga, będąca przede wszystkim zbiorem strategii stosowanych do osiaggania celów estetycznych i manipulacyjnych, to polityka obrazu. Obydwa czynniki łączy szczególna, specjalistyczna wiedza komunikatorów - sprawujących realną władzę i nadzór nad obydwoma biegunami procesu i mających dostęp do „rzeczywistości niezmediatyzowanej"s.

3 Koncepcja „Pastwo-komunikator” to konsekwencja mediatyzacji władzy politycznej, jak również wyznacznik obszaru ściśle związanego ze środowiskiem mediów. Na podstawie: G. Sartori, Videopolitica: Medios, Informacion y Democracia de Sondeo, USA 2003.

4 G. Sartori, Homo Videns. La sociedad teledirigida, Buenos Aires 1998, s. 78.

5 A. Ogonowska, Obrazy polityki. Polityka obrazu, „Kultura popularna” 2003, nr 2, s. 121-127. 
Należy podkreślić, iż video-polityka jest także definiowana jako proces, poprzez który środki społecznego komunikowania każdorazowo narzucają swoją logikę funkcjonowania konstruktorom rzeczywistości politycznej. W przebiegu tego procesu zmediatyzowane wizerunki rzeczywistości stają się podstawowymi aktorami, scenografiami oraz instrumentami polityki. O. Rincón wskazuje na dwoistość tego zjawiska: $\mathrm{w}$ pewnym sensie aktywności związane z video-polityką poszerzają całkowity obszar aktywności politycznej, przywracając czy też rekonstruując masową debatę, jednocześnie jednak odbierają jej wielowymiarowość, sens i esencję ${ }^{6}$. Warto zauważyć, że w ten sposób dokonuje się także znacząca transformacja - kandydat staje się symbolem medialnym, widzowie zaś zostają wprowadzeni w stan ciagłej kampanii wyborczej, zorientowanej wokół bodźców socjotechnicznych.

\section{Prywatne i publiczne środki komunikowania społecznego w Wenezueli}

Zgodnie z informacjami podanymi do publicznej wiadomości przez A. Pasquali ${ }^{7}$, rząd Hugo Cháveza kontrolował dziesięć $\mathrm{z}$ dwunastu otwartych stacji telewizyjnych $\mathrm{w}$ kraju, posiadając jednocześnie większościowe udziały w trzydziestu sześciu regionalnych stacjach telewizyjnych. W ramach działań nadzorowanego przez Cháveza rządu zainstalowano i sfinansowano ponad sto czterdzieści pięć radiostacji i osiemnaście społecznych stacji telewizyjnych, w większości o profilu prorządowym $^{8}$.

W tym kontekście niezbędne jest przybliżenie rozwiązań instytucjonalnych zastosowanych w Wenezueli w pierwszej dekadzie XXI wieku. W 2006 roku, jako struktura Ministerstwa Komunikacji i Informacji, powstał konglomerat narodowych środków komunikowania społecznego pod nazwą Narodowy System Mediów Publicznych Wenezueli (hiszp. Sistema Nacional de Medios Públicos de Venezuela). Nadrzędnymi

6 O. Rincón, Uribe tevé, cuando gobernar es una emoción televisiva, „Revista Número 46.” 2005, http://revistanumero.com/46/uribe.htm, 26.09.2012.

7 Antonio Pasquali to wenezuelski ekspert z zakresu komunikacji, profesor i były zastępca generalny UNESCO w sektorze Komunikacji.

${ }^{8}$ G. Delucchi, Gobierno de Venezuela acusó a otro Canal de TV, „El Morro Cotudo" 2007, www.elmorrocotudo.cl/admin/render/noticia/10361, 26.01.2013. 
- i deklarowanymi przez Ministerstwo w oficjalnym przekazie - funkcjami tej struktury są: specjalizacja każdego medium wchodzącego w jej skład (za pośrednictwem zintegrowanego zarządzania radiem, telewizją i multimediami), praca nad rozprzestrzenieniem informacji oraz realizacja misji publicznej - dbałość o jakość i odpowiedzialność za przekazywane informacje?

Warto zwrócić uwagę na wizerunek narodowych środków społecznego komunikowania propagowany i ustanawiany przez przedstawicieli wenezuelskiego rządu. Jak podano na stronie internetowej wenezuelskiego Ministerstwa Komunikacji i Informacji: Narodowy System Mediów Publicznych jest „najlepszym źródłem informacji pozwalających poznać rzeczywiste wydarzenia związane z wyborami prezydenckimi, jako że System ten jest zobowiązany do przekazywania prawdy”. Informacja ta została podana w oparciu o wystapienie Ministra Komunikacji i Informacji Andresa Izarra, który zaakcentował nowoczesność technologiczną przekazu mediów publicznych, dodając, iż narodowy konglomerat medialny „konfrontuje się z mediami prywatnymi w walce o prawdę w Wenezueli, która [...] pragnie rozwijać się w pluralizmie"10.

Niezbędne jest jednak określenie roli publicznych środków komunikowania społecznego w kontekście prywatnej sieci przekaźników medialnych. Istotne informacje dotyczące wycinka rzeczywistości medialnej - stacji telewizyjnych - pojawiają się w wyniku analizy danych statystycznych.

Tabela 1

Udzial wenezuelskiej publiczności telewizyjnej w latach 2000-2010 [dane w procentach]

\begin{tabular}{||c|c|c|c||}
\hline \hline Rok & $\begin{array}{c}\text { Prywatne stacje } \\
\text { telewizyjne (darmowe) }\end{array}$ & $\begin{array}{c}\text { Państwowe stacje } \\
\text { telewizyjne }\end{array}$ & $\begin{array}{c}\text { Prywatne stacje } \\
\text { telewizyjne (platne) }\end{array}$ \\
\hline 1 & 2 & 3 & 4 \\
\hline 2000 & $80,79-82,10$ & $1,63-2,97$ & $15,06-17,47$ \\
\hline 2001 & $78,93-81,46$ & $1,47-2,07$ & $16,98-19,20$ \\
\hline 2002 & $66,07-81,25$ & $1,64-9,66$ & $16,41-24,27$ \\
\hline 2003 & $80,95-87,53$ & $2,07-6,72$ & $10,04-12,33$ \\
\hline 2004 & $83,08-86,16$ & $2,52-6,96$ & $9,52-12,42$ \\
\hline
\end{tabular}

9 Na podstawie informacji ze strony internetowej wenezuelskiego Ministerstwa Komunikacji i Informacji, www.minci.gob.ve/2012/10/sistema-nacional-de-medios-publicos-es-la-mejor-fuente-estar-informado-el-7-o/, 26.01.2013.

10 Ibidem. 


\begin{tabular}{||c|c|c|c||}
\hline 1 & 2 & 3 & 4 \\
\hline 2005 & $85,42-88,34$ & $2,92-4,42$ & $8,74-11,36$ \\
\hline 2006 & $79,89-84,86$ & $4,14-7,82$ & $11,00-14,43$ \\
\hline 2007 & $65,21-75,76$ & $5,53-8,49$ & $18,48-29,16$ \\
\hline 2008 & $64,27-66,34$ & $5,37-7,47$ & $27,71-30,90$ \\
\hline 2009 & $62,84-65,75$ & $5,44-8,24$ & $28,00-30,23$ \\
\hline 2010 & $59,97-63,96$ & $4,39-5,63$ & $31,65-34,40$ \\
\hline
\end{tabular}

Źródło: Opracowanie własne na podstawie: AGB Panamericana de Venezuela Medición S.A. oraz artykułu Televisión en Venezuela: ¿quién domina los medios de comunicación? ${ }^{11}$.

Tabela 1. przedstawia udział wenezuelskiej publiczności telewizyjnej w latach 2000-2010; wprowadzono trzy kategorie: prywatne (darmowe) stacje telewizyjne, państwowe stacje telewizyjne (nadzorowane przez organy rządowe), prywatne (płatne) stacje telewizyjne (w tej kategorii zawierają się usługi satelitarne i usługi TV kablowej). Można zauważyć pewną, utrzymującą się w analizowanych latach, tendencję: udział publiczności w odbiorze państwowych stacji telewizyjnych wzrósł między rokiem 2000 a $2010 \mathrm{z}$ poziomu 1,6-2,97\% do poziomu 4,39-5,63\%, czyli o kilka punktów procentowych. Jednocześnie wzrósł udział publiczności w odbiorze płatnych, prywatnych stacji telewizyjnych (z poziomu $15,06-17,47 \% \mathrm{w}$ roku 2000 do poziomu $31,65-34,40 \% \mathrm{w}$ roku 2010). Tendencję spadkową obserwujemy w przypadku prywatnych, darmowych stacji telewizyjnych (z 80,79-82,10\% w roku 2000 do 59,97-63,96\% w roku 2010).

Jak zauważają M. Weisbrot i T. Ruttenberg, odnosząc się do rezultatów badania z roku 2009 i 2010: „Jako, że właściciele prywatnych stacji, w większości pozostają w politycznej opozycji do rządu, oczywistym jest, iż ponad 90\% programów oglądanych przez Wenezuelczyków nie jest prorządowa. Co więcej, duża część prywatnych mediów jest zdecydowanie antyrządowa, w sposób najbardziej ekstremalny [...]"12. M. Weisbrot i T. Ruttenberg podkreślają, że przekaz medialny w Stanach Zjednoczonych sugeruje, iż rząd Hugo Cháveza kontrolował środki komunikowania społecznego w sposób dominujący ${ }^{13}$. Jednakże dane

11 M. Weisbrot, T. Ruttenberg, Televisión en Venezuela: ¿quién domina los medios de comunicación?, Center for Economic and Policy Research, 2010, www.cepr.net/documents/publications/2010_12_venezuela_media_sp.pdf, 20.01.2013.

12 Ibidem.

13 Pisząc o wyborach do wenezuelskiego Zgromadzenia Narodowego we wrześniu 2010 roku, J. Diehl wspomniał na łamach „Washington Post” o „opanowaniu 
określające udział publiczności w odbiorze poszczególnych typów stacji telewizyjnych pozwalają stwierdzić jednoznacznie: transmisja telewizji publicznej jest odbierana przez mniej niż 10\% widzów. Przekaz, który jest centralnym przedmiotem zainteresowania mojej pracy badawczej, obejmuje obszar telewizyjnych przekaźników publicznych, które ustanawiają strukturę wspomnianego wcześniej „państwa-komunikatora”, jednocześnie jednak stanowiąc mniejszość w zbiorze wszystkich wenezuelskich przekaźników telewizyjnych.

\section{Aló, Presidente}

Szczególnym - i pionierskim w swojej formule - przykładem komunikowania politycznego, jak również polem uprawiania video-polityki był cotygodniowy, nadawany w niedziele, program telewizyjny Aló, Presidente emitowany od maja 1999 roku aż do połowy roku 2012 (zawieszony ze względu na chorobę prowadzącego). Powołany jako audycja wpisana w działalność Ministerstwa Ludowego Informacji i Komunikacji Wenezueli, był autorskim pomysłem prezydenta Hugo Cháveza, który pełnił rolę gospodarza, reżysera i głównego bohatera. Nadawany tradycyjnie z siedziby Radio Nacional de Venezuela, przez pierwszy rok pozostawał transmisją radiową, w roku 2000 przekształcając się w multimedialny - telewizyjny, internetowy i radiowy - talk show emitowany również poza granicami państwa (przede wszystkim na Dominikanie, Kubie, w Gwatemali i Brazylii ${ }^{14}$ ).

Początkowym założeniem twórców programu było wprowadzenie interakcji z obywatelami, słuchacze i widzowie mogli dzwonić w trakcie emisji na żywo i prowadzić rozmowę z Chávezem; w ten sposób implementowano wrażenie partycypacji politycznej; jak podano na oficjalnej

mediów przez reżim Cháveza"; podczas wywiadu udzielanego CNN L. Morillón z organizacji „Dziennikarze bez granic” stwierdziła, iż „Prezydent Chávez kontroluje większość stacji telewizyjnych". Na podstawie: J. Diehl, Is Hugo Chavez a Real Threat to the US?, „Washington Post” 2010, www.washingtonpost.com/wp-dyn/ content/article/2010/09/26/AR2010092603334.html, 20.05.2012; oraz CNN, Your World Today, http://archives.cnn.com/TRANSCRIPTS/0705/29/ywt.01.html, 20.05.2012.

14 Informacje pochodzą z oficjalnej strony programu Aló, Presidente, www.alopresidente.gob.ve, 10.09.2012. 
stronie programu: „Aló, Presidente stało się trybuną dla ludu” ${ }^{\text {. }}$. W późniejszych edycjach, środek ciężkości talk show przesunął się na funkcję informacyjną - prezydent przekazywał wiadomości o działalności rządu, prowadził też wywiady z podległymi sobie ministrami.

Niekiedy w programie dochodziło do ogłoszenia rozwiązań w ramach polityki publicznej - po raz pierwszy zapowiadano je na antenie, później wprowadzane w formie legislacyjnej, w ten sposób Aló, Presidente stało się areną podejmowania decyzji politycznych. Wyrazistym przykładem takiej działalności jest sytuacja z odcinka 306, w którym Chávez podczas rozmowy z Ministrem Obrony Narodowej Gustavo Rangelem wydał niespodziewanie rozkaz rozstawienia dziesięciu batalionów wojska na granicy z Kolumbią w odpowiedzi na atak FARC w Ekwadorze ${ }^{16}$.

Program był często nadawany spoza studia nagraniowego, z różnych punktów Wenezueli w których trwają tzw. Rządowe Misje Publiczne lub Dzieła (zwykle są to budowy, rekonstrukcje i renowacje obiektów użyteczności publicznej). W ten sposób Chávez przenosił się jeszcze bliżej każdego obywatela, stosując w swoim dyskursie zabiegi socjotechniczne mające jednoznacznie kolektywistyczny i przychylny ideom rewolucji boliwariańskiej charakter. Wielokrotnie w scenariusz programu włączane były pozdrowienia, listy czy podziękowania obywateli składane na ręce prezydenta jak również pozdrowienia, które Chávez przekazywał osobom znanym ze świata polityki - szczególnie z obszaru Ameryki Łacińskiej (na antenie wspomniano niejednokrotnie nazwiska Evo Moralesa, Cristiny Fernández czy Fidela Castro).

Rozpoznawalny i skonstruowany na bazie emocji styl komunikowania politycznego Hugo Cháveza określa E. Krauze pisząc: „W Aló, Presidente Chávez zapoczątkował styl nieznany w dotychczasowej polityce: rządzi »na żywo«, przed kamerami. Nie tylko sprawuje rządy, lecz także je odgrywa: rozkoszuje się swym głosem [...] przymyka oczy, krzyżuje ramiona, żegna się, patrzy w niebo, macha rękami, improwizuje, myśli na głos, wydaje rozkazy i je odwołuje, ogłasza niespodziewane decyzje

15 Na podstawie: Aló, Presidente: ¡Cómo un Presidente cautivó una audiencia, oyendo pasar los años!, Dirección Aló Presidente, www.alopresidente.gob.ve/histo$\mathrm{ria} / 28 / 1633,20.05 .2012$.

16 Y. O. Valdez, Presidente Chávez ordena movilización de tropas a frontera con Colombia, ElUniversal 2008,www.eluniversal.com/2008/03/02/chcol_ava_presidente-chavez-or_02A1400879.shtml, 24.11.2012. 
[...] odbiera wcześniej ustalone telefony, prowadzi monolog ze swoimi gośćmi, śpiewa, recytuje [...] W kraju telenowel Chávez wynalazł fantastyczny gatunek telewizyjny, o jakim nie śnili wielcy aktorzy sceny politycznej, jak np. Ronald Reagan"17.

Tabela 2

Czas trwania programu Aló, Presidente, odcinki

347-367 z 2010 roku

\begin{tabular}{||c|c|c||}
\hline Data emisji & Numer odcinka & Czas trwania \\
\hline $10 / 01 / 2010$ & 347 & $06: 23: 33$ \\
\hline $17 / 01 / 2010$ & 348 & $07: 12: 10$ \\
\hline $24 / 01 / 2010$ & 349 & $05: 53: 00$ \\
\hline $31 / 01 / 2010$ & 350 & $06: 22: 56$ \\
\hline $07 / 02 / 2010$ & 351 & $05: 50: 05$ \\
\hline $21 / 02 / 2010$ & 352 & $02: 11: 50$ \\
\hline $14 / 03 / 2010$ & 353 & $07: 02: 31$ \\
\hline $21 / 03 / 2010$ & 354 & $06: 08: 24$ \\
\hline $11 / 04 / 2010$ & 355 & $04: 20: 24$ \\
\hline $25 / 04 / 2010$ & 356 & $03: 52: 08$ \\
\hline $16 / 05 / 2010$ & 357 & $05: 09: 25$ \\
\hline $23 / 05 / 2010$ & 358 & $06: 01: 09$ \\
\hline $30 / 05 / 2010$ & 359 & $04: 30: 17$ \\
\hline $06 / 06 / 2010$ & 360 & $06: 32: 43$ \\
\hline $13 / 06 / 2010$ & 361 & $04: 54: 19$ \\
\hline $18 / 07 / 2010$ & 362 & $06: 52: 10$ \\
\hline $08 / 08 / 2010$ & 363 & $07: 13: 53$ \\
\hline $03 / 10 / 2010$ & 364 & $04: 32: 24$ \\
\hline $10 / 10 / 2010$ & 365 & $06: 03: 51$ \\
\hline $31 / 10 / 2010$ & 366 & $07: 39: 24$ \\
\hline $14 / 11 / 2010$ & 367 & $05: 21: 12$ \\
\hline & & $\mathbf{1 2 0 : 0 7 : 4 8}$ \\
\hline \hline
\end{tabular}

Źródło: Opracowanie własne na podstawie: $A G B$ Nielsen Media Research (2011).

Zgodnie z danymi z tabeli 2., większość transmisji Aló, Presidente trwała ponad 5 godzin, w ciagu całego 2010 roku w sumie wyemitowano

17 E. Krauze, Władza i obłęd. Najnowsza historia Wenezueli, Warszawa 2011, s. $63-64$. 
120 godzin programu. Najdłuższy odcinek audycji w analizowanym okresie trwał 7 godzin 39 minut i 24 sekundy (odcinek 366 z 31 października), z kolei najkrótszy odcinek trwał 2 godziny 11 minut i 50 sekund (odcinek 352 z 21 lutego). Y. González i A. Cañizález obliczyli, iż przyjmując za średni dzień pracy osiem (8) godzin, Hugo Chávez w 2010 roku spędził prawie miesiąc, sprawując urząd za pośrednictwem telewizji.

Na podstawie analizy początkowych pięciu minut (wycinek czasowy od 0:00 do 3:08) 374 odcinka Aló, Presidente przedstawię personalistyczną, intymną oś programu prowadzonego przez Hugo Cháveza, obecną w zbliżonej formie we wszystkich jego edycjach. Pierwsze sekundy audycji upływają na przywitaniu, które prezydent kieruje do wszystkich odbiorców, jednocześnie pozdrawiając Teresę Maniglia - reżysera programu oraz jego realizatorkę (akcentowana jest postawa oparta na spersonalizowanym kontakcie) i śpiewając radośnie (intencjonalne stwarzanie atmosfery familiarności programu). W drugiej minucie przekazu Chávez przeprasza za to, że program rozpoczyna się dopiero o godzinie trzynastej, tłumacząc iż jest to związane $z$ rehabilitacją po operacji i z zaleceniami lekarzy (zabieg mający na celu usytuowanie prezydenta w centrum programu, wywołujący współczucie i solidarność widzów i słuchaczy). Następnie przedstawia odbiorcom obecnego w studio wiceprezydenta Elíasa Jaua, mówiąc o wcześniejszym, serdecznym kontakcie $\mathrm{z}$ jednym z ministrów (nacisk na tworzenie wspólnoty, której epicentrum jest Hugo Chávez), wspomina także o tłumach oczekujących na zewnątrz (jego stwierdzenie ilustrują zdjęcia sprzed siedziby Radio Nacional de Venezuela), obiecuje, iż z pewnością pojawi się z pozdrowieniem dla swojego ludu (nawiązanie do tradycji monarchicznych). W tej samej sekwencji wprowadza też okrzyk onomatopeiczny wyrażający radość oraz bezpośredni zwrot do Wenezuelczyków zawarty w kolokwialnych zwrotach „compadre”, „comadre”, co w wolnym thumaczeniu oznacza „szwagier/szwagierka”, „kum/a”. W kontekście słonecznej pogody mówi o ponownym pojawieniu się Cháveza (wielokrotnie odnosi się do samego siebie w trzeciej osobie liczby pojedynczej) po dwutygodniowym wypoczynku zdrowotnym, dziękując za liczne dowody wsparcia ze strony obywateli (wymienia różne formy komunikacji, które zaszły pomiędzy zatroskanymi Wenezuelczykami a ich prezydentem). W trzeciej minucie przekazu gospodarz programu nawiązuje do rozpoczynającej się zimy, korzystając $\mathrm{z}$ okazji do pochwalenia gotowości sił rządowych na wszystkich szczeblach. Hugo Chávez prowadzi program ubrany w cha- 
rakterystyczny dres z motywem flagi Wenezueli (latynoamerykańscy medioznawcy często podkreślają wykorzystanie symboli narodowych przez prezydenta), na płaszczyźnie języka gestów odnosi się częstokroć do emocji (gest chwytania się za serce, podnoszenia rąk, etc.).

Personalizm funkcjonował jako element władzy sprawowanej przez Cháveza, wprowadzenie formuły „rząd to ja” w warstwie dyskursu politycznego powodował zatracenie instytucjonalnego charakteru władzy wykonawczej. Ponadto, stosowanie formuły „my” oznaczało ,ja - Chávez” (lub: rząd) razem z obywatelami - tworzono iluzję identyfikacji i partycypacji publicznej, symbolicznie przekraczano hierarchiczną barierę, zwykle w celu wskazania na powszechne poparcie dla zmian wprowadzanych w duchu Socjalizmu XXI wieku ${ }^{18}$. Inny kontekst dla użycia formuły „my” podczas audycji Aló, Presidente to sytuacja defensywna, w której Chávez odpierał krytykę zarządzania państwem.

Warto zwrócić uwagę na stosowanie wyrazistego zabiegu językowego - Hugo Chávez mówił o sobie w trzeciej osobie liczby pojedynczej w obliczu nacechowanych negatywnie aluzji, które napływały ze strony jego adwersaży; zabieg ten zmieniał charakter ataku, dokonało się przeniesienie krytyki personalnej na krytykę skierowaną wobec całego narodu: „Chávez Cię nie oszukał, nie, Chávez lata luksusowym samolotem i wydaje pieniądze narodu, nie, Chávez jest bogaty, Chávez żyje jak król, Chávez Cię oszukuje, Chávez Cię oszukał"19.

Wielowymiarowa narracja prowadzącego program obejmowała również zwroty stosowane przez obywateli, cytowane na antenie: „mój Prezydencie”, „Mój Komendancie”, „Nasz Przewodniku”. W odcinku 361 pojawia się zdanie, które można uznać za syntezę kultu Cháveza - wypowiada je podczas nagrania pracownica platformy wiertniczej ,[...] każdego dnia widziałam ten portret i mówiłam sobie, Mój Komendancie, spójrz na mnie, bo Ty jesteś mój i ja jestem Twoja Mój Prezydencie, Mój Prezydencie, Kocham Pana" 20 .

18 Budowa międzypaństwowej struktury opartej o ideę socjalizmu XXI wieku jest celem Zjednoczonej Partii Socjalistycznej Wenezueli, na czele której stoi prezydent Hugo Chávez. Autorem koncepcji jest Heinz Dieterich, który uznał, iż komunizm i kapitalizm nie są w stanie rozwiązać globalnych problemów ludzkości (wśród nich: problemu głodu, nierówności ekonomicznej, rasizmu, etc.), powstaje zatem zapotrzebowanie na nowy system - Socjalizm XXI wieku, oparty na demokracji bezpośredniej i antykapitalistycznej gospodarce wynikającej z teorii wartości.

19 Aló, Presidente, odcinek 366, http://alopresidente.gob.ve/, 12.01.2013.

20 Aló, Presidente, odcinek 361, http://alopresidente.gob.ve/, 14.01.2013. 
Podobnych komunikatów dostarcza strona internetowa Aló, Presidente - w warstwie wizualnej składająca się z licznych fotografii z wizerunkami Cháveza ${ }^{21}$, w warstwie tekstowej proponująca informacje wiadomości, reportaże, wywiady, świadectwa, opis Dzieł Państwowych oraz sekcję rozrywkową - tzw. Rytmy Narodu (zbiór tekstów i nagrań zespołów muzycznych popieranych i promowanych przez rząd Wenezueli). Wśród świadectw znajdziemy m.in. wyznanie traktorzystki pracującej dla Unii Własności Społecznej - ponownie w komunikowaniu politycznym środek ciężkości położono na więź familiarną i upowszechnianie symboli narodowych, podobnie w sekcji Dzieła - pojawiają się opisy oraz fotografie nowo powstałych budynków użyteczności publicznej wraz z krótkimi komentarzami zachwyconych mieszkańców. Imponujące w swojej objętości działy Multimedia i Materiały Aló zawierają wszystkie zapisy poprzednich programów (z możliwością darmowego, legalnego kopiowania), ich pełne transkrypcje oraz zdjęcia ilustrujące kolejne odcinki i biuletyn wydawany przy okazji każdej edycji programu (rozdawany za darmo na ulicach, w szkołach, w urzędach).

Jak zauważają Marcinkowski i Greger, personalistyczny charakter komunikowania politycznego w Wenezueli sprawia, iż w konsekwencji kandydat staje się symbolem medialnym, a obywatele w chwili korzystania z prawa głosu zwracają większą uwagę na obraz czy figurę osoby niż na jej pochodzenie partyjne. Fenomen ten podważa esencjonalną funkcję instytucji, jako wyznacznika państwowości o charakterze demokratycznym: ,[...] w demokracji podstawowym elementem jest funkcjonowanie, otwarty charakter i transparentność instytucji politycznych, drugoplanowa powinny pozostać szczegółowe czyny jej aktorów - grup i indywiduów",22.

Co więcej, w Wenezueli zjawisko video-polityki istnieje nie tylko na poziomie prezydenckim, ale też na szczeblu miast i miasteczek - burmistrz miasta Valencia Edgardo Parra prowadzi swój własny program w telewizji zatytułowany Władza Ludowa z Edgardo Parra (hiszp. Poder Popular con Edgardo Parra), z kolei gubernator Anzoátegui, Tarek Wiliam Saab, pojawia się regularnie w radiowo-telewizyjnym show $R a$ port Tareka (hiszp. Tarek Rinde Cuentas).

21 http://alopresidente.gob.ve/, 12.01.2013.

22 F. Marcinkowski, V. Greger, La personalización de la comunicación política en la televisión ¿Un resultado de la „americanización'?, „Relación entre política y medios" 2002, s. 255-278. 


\section{Podsumowanie}

Zarówno ze względu na format programu, jak i na szczególny styl retoryczny i rodzaj dyskursu stosowany przez Cháveza, Aló, Presidente spotkał się z krytyką wenezuelskiej opozycji - audycję uznano za formę „interwencjonizmu rządowego w publicznych środkach masowego komunikowania"23, praktycznie nieograniczoną czasowo i przestrzennie. Merytoryczna warstwa programu, zawierająca elementy charakterystyczne dla infotainment ${ }^{24}$ czy infomercial ${ }^{25}$, również stała się płaszczyzną krytyki - opozycyjni medioznawcy ocenili negatywnie różnorodność tematyczną i niespójność kolejnych wydań Aló, Presidente, uznając, że interpretacja popularnych piosenek, aluzje związane z boliwariańską przeszłością, wykorzystanie symboli religijnych i nawoływanie do konfrontacji z wrogiem są populistyczną propagandą ${ }^{26}$.

Video-politykę można uznać za strategię medialną służącą konsolidacji wizerunku władzy wykonawczej w Wenezueli. Powstało „państwo-komunikator", które emituje tylko jedną informację i tylko za pośrednictwem jednego przekaźnika: prezydenta Cháveza. Przestrzeń analizowanego programu telewizyjnego powstała w celu wykreowania swoistej agory powszechnej partycypacji, stopniowo zamieniając się w miejsce-medium, z którego prowadzi się rządy. Wykorzystanie równościowego, spolaryzowanego i personalistycznego dyskursu miało na celu dotarcie do sfery emocjonalnej odbiorców i uzyskanie pełnej identyfikacji obywateli z tele-prezydentem.

Istotnym aspektem pozostawał personalizm polityczny wyrażany w konstrukcjach gramatycznych przekazywanych komunikatów i w użyciu zaimka osobowego ,ja”, stwarzającego synonimiczną zależność pomiędzy instytucjami rządowymi i osobą Hugo Cháveza - w ten sposób

23 E. Díaz Rangel, M. Tremamunno, Chávez y Los Medios de Comunicación Social, Caracas 2002, s. 34-45.

24 Infotainment w definicji Oksfordzkiego Słownika Jezzyka Angielskiego to „,materiał emitowany przez media elektroniczne, mający jednocześnie informować i bawić; prezentowanie informacji w sposób rozrywkowy".

25 Infomercial zgodnie $\mathrm{z}$ internetową wersją słownika Business Dictionary to pełnometrażowy program handlowy (zwykle 15 do 30 minut czasu trwania) przedstawiony bardziej jako talk show, niż jako program promocyjny. W przypadku Aló, Presidente sprzedawanym ,produktem” były poglądy i działania polityczne Hugo Cháveza.

26 E. Díaz Rangel, M. Tremamunno, Chávez y Los Medios..., op. cit., s. 98. 
proces podejmowania decyzji politycznych stało się procesem podejmowania decyzji medialnych, w którym przeważają improwizacja i atrakcyjność samego aktu wyrażania decyzji. Podsumowując, wykorzystanie video-polityki jako strategii medialnej oraz środków takich jak kult jednostki, afirmacja lidera czy wywoływanie zbiorowych emocji odbiorców, prowadziły do konsolidacji wizerunku władzy wykonawczej w Wenezueli.

\section{Political Communication in Latin America on the example of the activity of Venezuela President Hugo Chávez}

\section{Summary}

The transformation of the political communication models in Venezuela and other Latin American states is related to the evolving political culture in this region, together with a bold use of media communication approached both as a means and a goal. Video-politics, defined as a process of the mediatization of the constructs of political reality, is becoming a key notion for the citizens and voters there. Using the public means of social communication Hugo Chávez has made the Aló, Presidente show an arena of political decision-making and a space focused on political personalism. An analysis of selected elements of the show provides detailed information on the rhetorical tools and other mechanisms of exerting influence applied by Hugo Chávez. On a macro-scale the media strategies applied in the show turn out to be instruments of consolidating the image of executive power in Venezuela. 
